\title{
A general model for single-sludge wastewater treatment systems
}

\author{
Henze, Mogens; Leslie Grady Jr, C. P. ; Gujer, W.; Marais, G. V. R.; Matsuo, T.
}

Published in:

Water Research

Publication date:

1987

Document Version

Early version, also known as pre-print

Link back to DTU Orbit

Citation (APA):

Henze, M., Leslie Grady Jr, C. P., Gujer, W., Marais, G. V. R., \& Matsuo, T. (1987). A general model for singlesludge wastewater treatment systems. Water Research, 21(5), 505-515.

\section{General rights}

Copyright and moral rights for the publications made accessible in the public portal are retained by the authors and/or other copyright owners and it is a condition of accessing publications that users recognise and abide by the legal requirements associated with these rights.

- Users may download and print one copy of any publication from the public portal for the purpose of private study or research.

- You may not further distribute the material or use it for any profit-making activity or commercial gain

- You may freely distribute the URL identifying the publication in the public portal

If you believe that this document breaches copyright please contact us providing details, and we will remove access to the work immediately and investigate your claim 


\section{ABBREVIATED REPORT* \\ A GENERAL MODEL FOR SINGLE-SLUDGE WASTEWATER TREATMENT SYSTEMS}

In 1983 IAWPRC formed a task group to facilitate the application of practical models to the design and operation of biological wastewater treatment systems. This paper is a summary of the report prepared by the task group. It presents the model development for single-sludge systems performing carbon oxidation, nitrification and denitrification. The model includes eight fundamental processes: aerobic growth of heterotrophic biomass, anoxic growth of heterotrophic biomass, aerobic growth of autotrophic biomass, decay of heterotrophic biomass, decay of autotrophic biomass, ammonification of soluble organic nitrogen, hydrolysis of entrapped particulate organic matter, and hydrolysis of entrapped organic nitrogen. Methods are suggested for characterization of wastewaters and estimation of parameter values in ways consistent with the model. Finally, techniques are presented by which the model may be implemented for both education and engineering practice.

The Task Group comprised:

M. Henze, Chairman

Department of Environmental Engineering, Building 115, Technical University of Denmark, DK-2800 Lyngby, Denmark

C. P. Leslie Grady JR

Department of Environment Systems Engineering, College of Engineering, Clemson University, Clemson, SC 29634-0910, U.S.A.

W. GUJER

EAWAG, Swiss Federal Institute for Water Resources \& Water Pollution Control, CH-8600 Dubendorf, Switzerland

G. V. R. MARAIS

Department of Civil Engineering, University of Cape Town, Rondebosch, C.P., Republic of South Africa

T. Matsuo

Department of Urban Engineering, University of Tokyo, 7-3-1 Hongo, Bunkyo, Tokyo 113, Japan

Key words-mathematical modeling, biological wastewater treatment, nitrification, denitrification

\section{INTRODUCTION}

Mathematical models are powerful tools by which the designers of biological wastewater treatment systems can investigate the performance of a number of potential systems under a variety of conditions. They are particularly useful for those who are working with systems in which carbon oxidation, nitrification and denitrification are accomplished with a single sludge because the competing and parallel reactions in such systems are so complicated that it is difficult to estimate intuitively their responses to changes in system configuration or load. Unfortunately, in spite of the benefits to be gained from the use of models, many engineers have not yet incorporated them into their routine practice. This is due in part to the fact

*The full report is available as the IAWPRC Scientific and Technical Report No. 1, which can be obtained from IAWPRC, 1, Queen Anne's Gate, London SW1H 9BT, U.K. that models have often been perceived as research tools required sophisticated computer systems. With the widespread introduction of microcomputers, however, it is now possible for every design office to use process simulation models on a regular basis.

Recognizing the benefits to be derived from the routine use of mathematical modeling, the IAWPRC in 1983 formed a task group to promote the development and facilitate the application of practical models to the design and operation of biological wastewater treatment. The goal was to review existing models and to reach a consensus concerning the simplest one have the capability of realistic predictions of the performance of single sludge systems carrying out carbon oxidation, nitrification and denitrification. The model was to be presented in a way that made clear the processes incorporated into it and the procedures for its use. The group completed its task and submitted its final report in 1986. That report will be published in total in the new IAWPRC series entitled IAWPRC Scientific and 
Table 1. Process kinetics and stoichiometry for

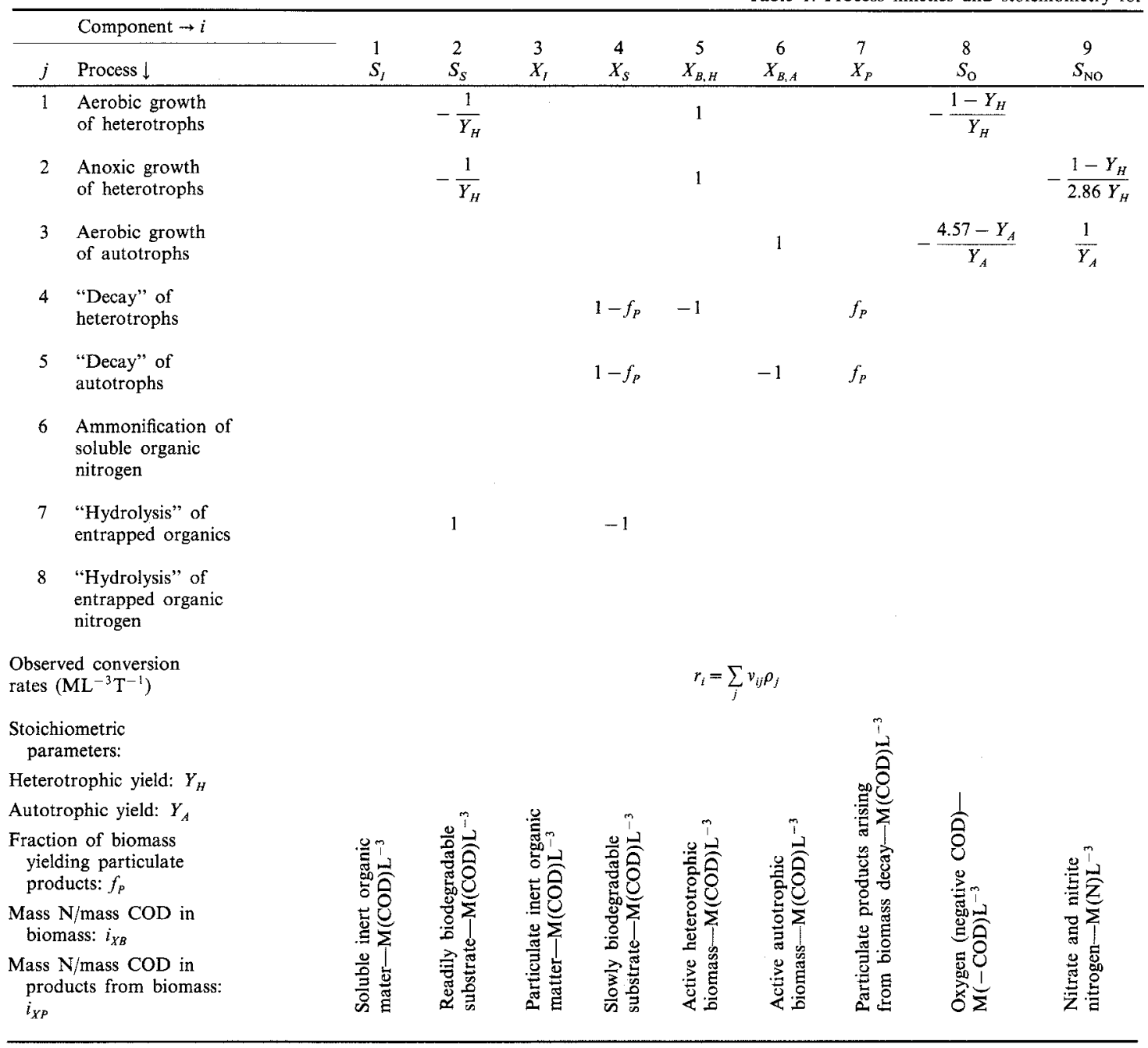

Technical Reports. The purpose of this paper is to present the major points of the report to the broad IAWPRC membership. Readers desiring more detail are urged to consult the full report.

\section{THE MODEL}

The essential features of the model selected by the task group are presented in matrix format (Peterson, 1965 ) in Table 1. The information in that table allows construction of the rate equations describing the fate of each component for inclusion in mass balance equations appropriate for the particular wastewater treatment system being modeled. All components in the model are listed by symbol across the top of the table while their definitions are given across the bottom. The nomenclature employed is consistent with that recommended by IAWPRC (Grau et al., 1982). All fundamental processes which are important in single-sludge systems are listed down the extreme left column while the rate expressions chosen to represent them are listed on the extreme right. The parameters in those rate expressions are defined in the lower right corner. The body of the matrix contains the stoichiometric coefficients, which are defined in the lower left corner. If a particular process has no impact upon a given component, then the box formed by the intersection of the process row and component column is blank.

The model contains certain features that should be recognized. First, the concentrations of all organic components, whether soluble $(S)$ or particulate $(X)$, are given in units of chemical oxygen demand (COD). This simplifies the stoichiometric coefficients and reduces the number of conversion factors required. It also allows calculation of the oxygen requirement by a simple COD balance (Gaudy and Gaudy, 1971). One consequence of this standard is that the concentrations of biomass and other particulates contributing to the mixed liquor volatile suspended solids must be multiplied by an appropriate factor to put them into mass units. The concentrations of all nitrogen species are given as nitrogen. Consequently, two conversion factors (2.86 and 4.57$)$ must be used 
carbon oxidation, nitrification, and denitrification

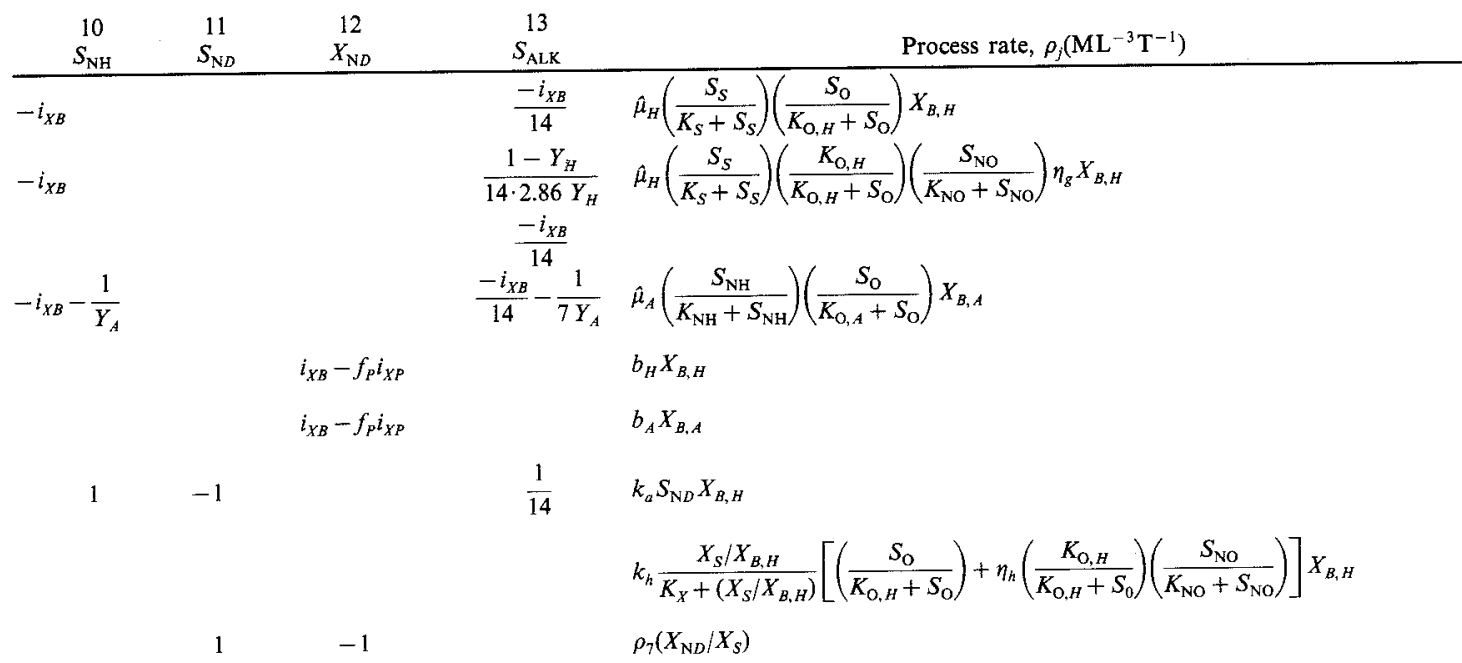

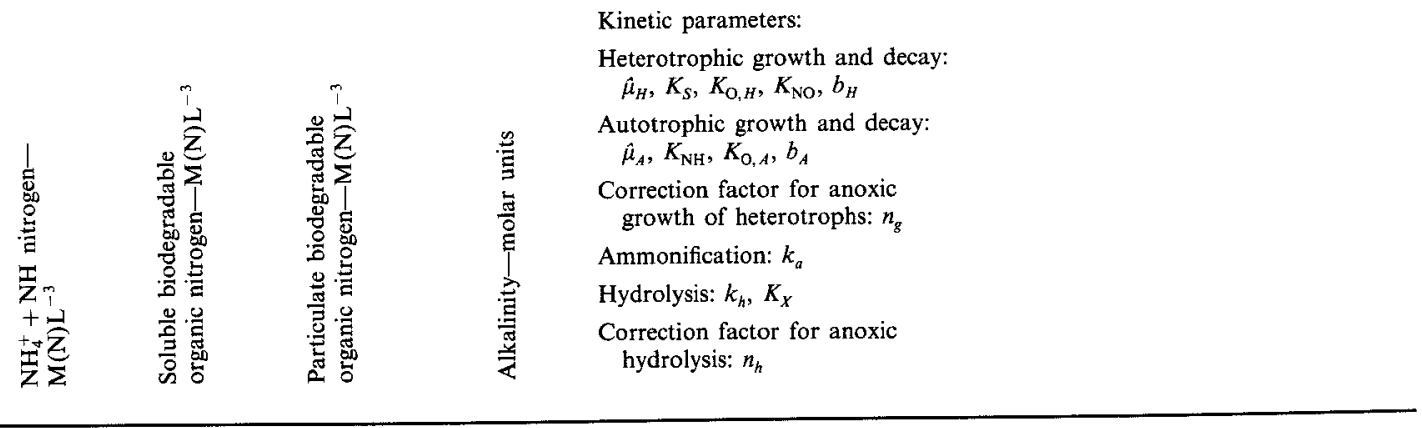

in the matrix to convert nitrate nitrogen and ammonia nitrogen concentrations, respectively, to an equivalent COD basis for calculating the utilization rates of oxygen or nitrate. Finally, no inorganic particulate materials are included in the model because they do not enter into reactions or contribute to the COD. Their contribution to the total mixed liquor suspended solids concentration in any reactor can be computed by multiplying their concentrations in the feed stream by the ratio of the concentration of particulate inert organic matter $\left(X_{I}\right)$ in the reactor to the concentration in the feed stream.

The advantage of the matrix format in Table 1 is that it allows the reader to see at one time the impact of all potential conversion processes on all possible components. To conserve space, reference to a given component undergoing a particular reaction will sometimes be referred to by a shorthand notation, $C_{i} R_{j}$, where $C_{i}$ refers to component $i$ in column $i$ and $R_{j}$ means reaction $j$ in row $j$. Construction of the observed conversion rate for a component is accomplished by moving down the column $i$ corresponding to that component and summing the product of each process rate $\rho_{j}$ times the appropriate stoichiometric coefficient, $v_{i j}$

$$
r_{i}=\sum_{j} v_{i j} \rho_{j}
$$

For example, the observed conversion rate for readily biodegradable substrate (component 2 ) is

$$
r_{2}=v_{21} \rho_{1}+v_{22} \rho_{2}+v_{27} \rho_{7}
$$

or

$$
\begin{aligned}
r_{2}= & -\frac{1}{Y_{H}} \hat{\mu}_{H}\left(\frac{S_{S}}{K_{S}+S_{S}}\right)\left(\frac{S_{\mathrm{O}}}{K_{\mathrm{O}, H}+S_{\mathrm{O}}}\right) X_{B, H} \\
& -\frac{1}{Y_{H}} \hat{\mu}_{H}\left(\frac{S_{S}}{K_{S}+S_{S}}\right)\left(\frac{K_{\mathrm{O}, H}}{K_{\mathrm{O}, H}+S_{\mathrm{O}}}\right) \\
& \times\left(\frac{S_{\mathrm{NO}}}{K_{\mathrm{NO}}+S_{\mathrm{NO}}}\right) \eta_{g} X_{B, H} \\
& +k_{h} \frac{X_{S} / X_{B, H}}{K_{X}+\left(X_{S} / X_{B, H}\right)}\left[\left(\frac{S_{\mathrm{O}}}{K_{\mathrm{O}, H}+S_{\mathrm{O}}}\right)\right. \\
& \left.+\eta_{h}\left(\frac{K_{\mathrm{O}, H}}{K_{\mathrm{O}, H}+S_{\mathrm{O}}}\right)\left(\frac{S_{\mathrm{NO}}}{K_{\mathrm{NO}}+S_{\mathrm{NO}}}\right)\right] X_{B, H} .
\end{aligned}
$$


The observed reaction rates can be substituted into mass balance equations depicting the fates of the components within appropriate system boundaries to formulate a model for any particular biological treatment system.

In selecting the components and process rate equations in Table 1 the task group focused on those that were essential to a realistic simulation, yet were simple enough to facilitate the model solution. A1though such rate expressions may not depict perfectly the actual occurring within a system they can be used satisfactorily as long as they mimic well the outcome of those events. All papers influencing the thinking of the task group cannot be cited here. Nevertheless, attention should be called to the work of Dold et al. (1980), Van Haandel et al. (1981) and Dold and Marais (1986) because of their extensive bibliographies and their synthesis of the information contained therein. The latter paper is particularly important because it tested an earlier version of the model proposed by the task group (Grady et al., 1986) and expanded it to its present form. In doing so it presented excellent verification of the model presented here.

Examination of the process rate expressions in Table 1 reveals that the task group employed the concept of switching functions to turn them on and off as environmental conditions are changed. This was particularly necessary for process that depend upon the type of electron acceptor (oxygen or nitrate) present. For example, the bacteria which are responsible for nitrification are capable of growth only under aerobic conditions (oxygen present) and their rate of growth will fall to zero as the dissolved oxygen (DO) concentration approaches zero, regardless of the concentration of their energy yielding substrate. This can be modeled by including a DO "switch" in the process rate equations. The form adopted by the task group was

$$
\text { oxygen switching function }=\frac{S_{\mathrm{O}}}{K_{\mathrm{O}}+S_{\mathrm{O}}} .
$$

The selection of a small value for $K_{\mathrm{O}}$ means that the value of the switching function is near unity for moderate DO concentrations but decreases to zero as the DO concentration approaches zero. The fact that the function is mathematically continuous helps to eliminate problems of numerical instability which can occur during simulations with models which include rate equations that are switched on and off discontinuously. Similar, processes which occur only when DO is absent may be turned on by a switching function of the form

$$
\frac{K_{\mathrm{O}}}{K_{\mathrm{O}}+S_{\mathrm{O}}}
$$

Because of the long solids retention times (SRTs) and low specific growth rates incorporated into the design of most biological wastewater treatment sys- tems, differences in effluent soluble biodegradable substrate concentration among different system configurations generally are small. Conversely, large differences in activated sludge concentration and electron and acceptor requirement are common. Furthermore, good design practice requires that adequate electron acceptor be supplied in response to both real-time and space-time (location) dependent changes in demand and that final settlers and sludge return systems be capable of handling all anticipated concentrations of solids. This suggests that models depicting substrate removal are important more for their impact upon activated sludge concentration and electron acceptor requirements than for their ability to predict effluent substrate concentration. Consequently, primary consideration was given by the task group to prediction of activated sludge concentrations during selection of process stoichiometry and to estimation of electron acceptor requirements during development of the process rate expressions. Nevertheless, it is apparent that the values of switching constants like $K_{\mathrm{O}}$ will influence those predictions even though the forms of equations (4) and (5) were chosen more for their mathematical convenience than for conformance to any fundamental rate laws. Consequently, care should be taken in the selection of the values for switching constants to ensure that model predictions are not biased.

The organic matter in a wastewater may be subdivided into a number of categories (McKinney and Ooten, 1969; Dold et al., 1980). The first important subdivision is based on biodegradability.

Nonbiodegradable organic matter is biologically inert and passes through an activated sludge system unchanged in form. Two fractions can be identified, depending on their physical state: soluble and particulate. Inert soluble organic matter $\left(S_{I}\right)$ leaves the system at the same concentration that it enters. Inert suspended organic matter $\left(X_{I}\right)$ becomes enmeshed in the activated sludge and is removed from the system through sludge wastage. Because the waste sludge flow rate is smaller than the system inflow rate, a mass balance requires the concentration of $X_{I}$ in the system to be higher than in the influent.

Biodegradable organic matter may be divided into two fractions: readily biodegradable $\left(S_{S}\right)$ and slowly biodegradable $\left(X_{S}\right)$. The readily biodegradable material, which consists of simple molecules, is treated as if it were soluble whereas the slowly biodegradable material, consisting of complex molecules, is treated as if it were particulate, although some may indeed be soluble.

Readily biodegradable material is considered to be the only substrate for growth of heterotrophic biomass $\left(X_{B, H}\right)$ which can take it in [see column 2, row $1\left(\mathrm{C}_{2} \mathrm{R}_{1}\right)$ and column 2 , row $2\left(\mathrm{C}_{2} \mathrm{R}_{2}\right)$ in Table 1] and convert it into new biomass under either aerobic $\left(C_{5} R_{1}\right)$ or anoxic (oxygen absent, nitrite present) $\left(C_{5} R_{2}\right)$ conditions. The electrons associated with the expenditure of energy for cell synthesis are trans- 
ferred to the exogeneous electron acceptors [oxygen $\left(C_{8} R_{1}\right)$ or nitrate $\left.\left(C_{9} R_{2}\right)\right]$.

Slowly biodegradable substrate is considered to be removed from suspension instantaneously by entrapment in the biofloc. However, once there, it must be acted upon extracellularly $\left(\mathrm{C}_{4} \mathrm{R}_{7}\right)$ and converted into readily biodegradable substrate $\left(C_{2} R_{7}\right)$ before it can be used by the heterotrophic biomass for growth. The reactions involved in this conversion are called "hydrolysis" in the model, although in reality they are likely to be more complex. It is assumed that hydrolysis involves no energy utilization and thus there is no utilization of electron acceptor associated with it; i.e. there is no stoichiometric coefficient at $\mathrm{C}_{8} \mathrm{R}_{7}$ or $\mathrm{C}_{9} \mathrm{R}_{7}$.

The degradation of slowly biodegradable substrate is very important to realistic modeling of activated sludge systems because it is primarily responsible for the attainment of realistic space-time and real-time dependent electron acceptor profiles. Careful examination of all available literature revealed that very little experimental work has been conducted specifically on the kinetics and mechanisms of degradation of particulate organic material. Nevertheless, that literature revealed that certain features were required in order for the overall system models to give realistic electron acceptor profiles. One was that the rate was first order with respect to the active heterotrophic biomass present. Another was that the rate appeared to saturate as the amount of entrapped substrate became large in proportion to the biomass. In addition, the rate of hydrolysis is usually considerably lower than the specific rate of utilization of readily biodegradable substrate so that it becomes the rate limiting factor in the growth of biomass when only slowly biodegradable substrate is present in the feed to a reactor. Furthermore, because of the need for enzyme synthesis it was reasoned that the rate would be dependent on the concentration of the electron acceptor present and would be lower under anoxic conditions than under aerobic ones. Finally, hydrolysis is apparently completely stopped during short anaerobic (neither oxygen nor nitrate are present) periods for organisms of the type found in activated sludge (Van Haandel et al., 1981). Examination of row 7 in Table 1 shows that all of these features were incorporated into the rate expression.

Heterotrophic biomass is generated by growth on readily biodegradable substrate under either aerobic $\left(C_{5} R_{1}\right)$ or anoxic $\left(C_{5} R_{2}\right)$ conditions but its generation is assumed to stop under anaerobic conditions. Biomass is lost by decay $\left(C_{5} R_{4}\right)$, which incorporates a large number of mechanisms including endogenous metabolism, death, predation and lysis. The most common technique for modeling decay under aerobic conditions is to incorporate all of the mechanisms into a single rate expression which is first order with respect to the concentration of active biomass and to let each unit of biomass COD lost result in the utilization of an equivalent amount of oxygen (Grady and Lim, 1980). This approach, however, causes problems when other electron acceptors are considered. To avoid those problems, the approach adopted was basically that of Dold et al. (1980) and it is depicted in row 4 of Table 1 . There it can be seen that a first order rate expression is retained. The rate coefficient, however, is different in both concept and magnitude from the usual decay coefficient. In this case, decay acts to convert biomass $\left(\mathrm{C}_{5} \mathrm{R}_{4}\right)$ to a combination of slowly biodegradable substance $\left(C_{4} R_{4}\right)$ and particulate products $\left(C_{7} R_{4}\right)$ which are inert to further biological attack. The latter are similar in concept to the endogenous mass of McKinney and Ooten (1969) and act to reduce the viability of the suspended solids in a bioreactor (Weddle and Jenkins, 1971). No loss of COD is involved in this split and no electron acceptor is utilized. Furthermore, decay continues at a constant rate regardless of the type of electron acceptor present. The use of electron acceptor normally associated with decay occurs as a result of cell growth on the readily biodegradable substrate which arises from hydrolysis of the slowly biodegradable substrate released by decay. If conditions are aerobic, oxygen will be used $\left(\mathrm{C}_{8} \mathrm{R}_{1}\right)$. If conditions are anoxic, nitrate will be used $\left(C_{9} R_{2}\right)$. If neither oxygen nor nitrate available, no conversion occurs and the slowly biodegradable substrate accumulates. Only when aerobic or anoxic conditions are resumed will it be converted and used. A portion of the biomass lost by decay is reconverted into new biomass via the use of the readily biodegradable substrate resulting from the slowly biodegradable substrate released. Because of this reconversion, the rate coefficient must be higher to give the same net loss of biomass as in the conventional method of modeling decay.

Nitrogenous matter in a wastewater, like carbonaceous matter, can be divided into two categories, nonbiodegradable and biodegradable, each with further subdivisions. With respect to the nonbiodegradable fraction, the particulate portion is that associated with the nonbiodegradable particulate COD; the soluble portion usually is negligibly small and is not incorporated into the model. The biodegradable nitrogenous matter may be subdivided into ammonia (both free and saline) $\left(S_{\mathrm{NH}}\right)$, soluble organic nitrogen $\left(S_{\mathrm{N} D}\right)$ and particulate organic nitrogen, $\left(X_{\mathrm{N} D}\right)$. Particulate organic nitrogen is hydrolyzed $\left(C_{12} R_{8}\right)$ to soluble organic nitrogen $\left(C_{11} R_{8}\right)$ in parallel with hydrolysis of slowly biodegradable organic matter. The soluble organic nitrogen is acted on by heterotrophic bacteria $\left(C_{11} R_{6}\right)$ and converted to ammonia $\left(C_{10} R_{6}\right)$. The ammonia serves as the nitrogen supply for synthesis of heterotrophic $\left(C_{10} R_{1}, C_{10} R_{2}\right)$ and autotrophic $\left(\mathrm{C}_{10} \mathrm{R}_{3}\right)$ biomass and as the energy supply $\left(C_{10} R_{3}\right)$ for growth of autotrophic nitrifying bacteria $\left(C_{6} R_{3}\right)$. For simplicity, the autotrophic conversion of ammonia $\left(C_{10} R_{3}\right)$ to nitrate $\left(C_{9} R_{3}\right)$ nitrogen is considered to be a single-step process which requires oxygen $\left(C_{8} R_{3}\right)$. The nitrate formed may serve 
as terminal electron acceptor for heterotrophic bacteria under anoxic conditions $\left(\mathrm{C}_{9} \mathrm{R}_{2}\right)$, yielding nitrogen gas. Cell decay of either autotrophic or heterotrophic biomass leads to release of particulate organic nitrogen $\left(C_{12} R_{4}, C_{12} R_{5}\right)$ which can re-enter the cycle.

Autotrophic biomass is formed $\left(C_{6} R_{3}\right)$ by growth at the expense of ammonia nitrogen $\left(\mathrm{C}_{10} \mathrm{R}_{3}\right)$ under aerobic conditions. The decay of autotrophs $\left(\mathrm{C}_{6} \mathrm{R}_{5}\right)$ is handled in exactly the same manner as the decay of heterotrophs. The justification for this is the likelihood that the decay observed in enrichment cultures of autotrophic bacteria is actually due to predation and lysis, with subsequent growth of adventitious heterotrophic bacteria on the lysis products.

The final constituent included in the model is total alkalinity (column 13). Although its inclusion is not essential, it is desirable because it provides information whereby undue changes in $\mathrm{pH}$ can be predicted and avoided. All reactions involving addition or abstraction of protons will cause changes in alkalinity, but the ones of primary importance here involve nitrogen (Scearce et al., 1980; Downing et al., 1964) as shown in Table 1. From equilibrium chemistry of the carbonate system, if total alkalinity falls below about $50 \mathrm{~g} \mathrm{~m}^{-3}$ as $\mathrm{CaCO}_{3}$ then the $\mathrm{pH}$ becomes unstable and can fall to values well below 6 (WRC, 1984). Low $\mathrm{pH}$ decreases the nitrification rate and causes other problems such as corrosive and aggressive effluents, bulking, etc. Inclusion of the proper input term in a mass balance equation for alkalinity permits a user to evaluate whether the process configuration under consideration allows sufficient recovery of alkalinity during denitrification to maintain the $\mathrm{pH}$ in the proper range regardless of the proton release during nitrification. If not, then appropriate chemicals, such as lime, must be added to maintain the proper $\mathrm{pH}$.

\section{CHARACTERIZATION OF WASTEWATER AND ESTIMATION OF PARAMETER VALUES}

The model contains 13 components and 19 parameters. Fortunately, eight of the parameters show little variation from waste to waste and may be considered to be constants. They are listed in Table 2. The others must be evaluated on a case by case

Table 2. Parameters and characteristics which may be assumed

\begin{tabular}{ll}
\hline Symbol & Name \\
\hline$Y_{A}$ & Yield for autotrophic biomass \\
$b_{A}$ & Decay coefficient for autotrophic biomass \\
$f_{P}$ & Fraction of biomass leading to particulate products \\
$i_{X B}$ & Mass of nitrogen per mass of COD in biomass \\
$i_{X P}$ & Mass of nitrogen per mass of COD in products from \\
& biomass \\
$K_{\mathrm{O}, H}$ & Oxygen half-saturation coefficient for heterotrophic \\
$K_{\mathrm{NO}}$ & biomass \\
$K_{\mathrm{O}, A}$ & Nitrate half-saturation coefficient for denitrifying \\
& Oxygen half-saturation coefficient for autotrophic \\
\hline
\end{tabular}

basis. All of the components except $X_{P}$ may appear in the influent to the activated sludge system. They must be evaluated in concert with the stoichiometric parameters. In the following, the subscript 1 on a constituent represents its concentration in the bioreactor feed.

Characterization of wastewater and estimation of stoichiometric coefficients

Because of the operational definitions of many model constituents they must be determined experimentally in a way which is consistent with the assumptions in the model. Evaluation of both the wastewater characteristics and the model coefficients will be expedited if completely mixed activated sludge reactors are operated at steady state in an aerobic mode at a number of SRTs.

The total COD in the influent wastewater is made up of four constituents:

$$
\text { Influent COD }=S_{S 1}+X_{S 1}+S_{I 1}+X_{I 1} .
$$

To determine $S_{I 1}$, the concentration of inert soluble organic matter, remove an aliquot of the reactor contents from one of the completely mixed reactors being operated at an SRT in excess of 10 days and aerate it in a batch reactor. Remove samples periodically and analyze them for soluble COD. The final stable residual value is $S_{I 1}$.

Before the concentration of readily biodegradable substrate, $S_{S 1}$, can be obtained, the heterotrophic yield, $Y_{H}$, must be known. A sample of wastewater should be settled, filtered to remove the particulate material, and seeded lightly with acclimated biomass from one of the completely mixed reactors. Aliquots should be removed periodically and both the soluble COD and the total COD determined. The heterotrophic yield can be determined from the following:

$$
\begin{gathered}
\text { Cell } \mathrm{COD}=\text { total } \mathrm{COD}-\text { soluble } \mathrm{COD}, \\
Y_{H}=\frac{\Delta \text { cell } \mathrm{COD}}{\Delta \text { soluble } \mathrm{COD}}
\end{gathered}
$$

If this is done several times, an approximate $Y_{H}$ value may be determined. Any errors in this estimate will be compensated for in the determination of other parameters or influent concentrations.

The value of $S_{S 1}$ can be estimated by measuring the change in oxygen utilization rate in a single completely mixed reactor operated at an SRT near 2 days under a daily cyclic square wave feeding pattern $(12 \mathrm{~h}$ with feed; $12 \mathrm{~h}$ without feed) (Ekama et al., 1986). As shown in Fig. 1, there is a rapid drop in oxygen uptake rate following feed termination which is associated only with the readily biodegradable material and can be used to find its concentration:

$$
S_{S 1}=\frac{(\Delta \text { OUR })(V)}{Q\left(1-Y_{h}\right)},
$$




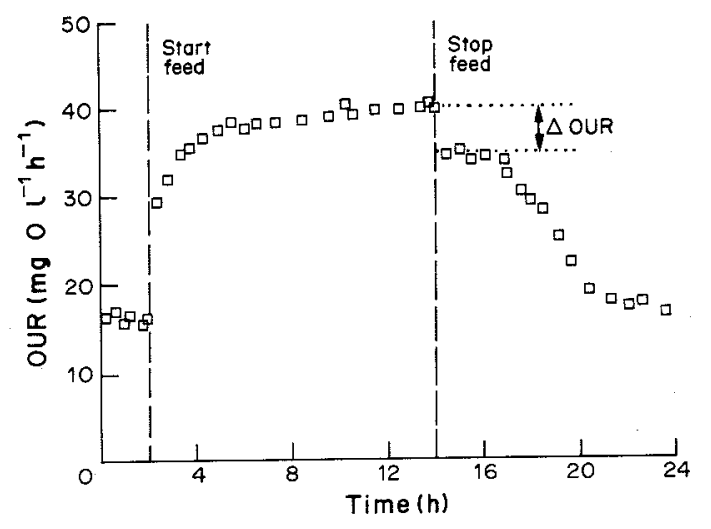

Fig. 1. Response of a completely mixed activated sludge reactor to a $12 \mathrm{~h}$ square wave response as used to determine the concentration of readily biodegradable substrate. From Ekama et al. (1986).

where

$\Delta$ OUR $=$ change in oxygen utilization rate following feed termination $\left(\mathrm{ML}^{-3} \mathrm{~T}^{-1}\right)$

$V=$ reactor volume $\left(\mathrm{L}^{3}\right)$

$Q=$ feed flow rate prior to termination $\left(\mathrm{L}^{3} \mathrm{~T}^{-1}\right)$

Having determined the concentrations in the wastewater of the total COD, readily biodegradable COD, and the inert soluble COD, it is only necessary to determine either the COD of the inert suspended organic matter $\left(X_{I 1}\right)$ or the COD of the slowly biodegradable substrate $\left(X_{S 1}\right)$ because the other can be determined by difference using equation (6). It is recommended that $X_{I 1}$ be evaluated as a parameter for fitting the model to data showing the effect of SRT on sludge production in the steady-state completely mixed activated sludge reactors. If the contribution of autotrophic biomass is neglected, the unknowns in the model are $X_{I 1}, X_{S 1}, f_{P}, b_{H}, S_{S}, k_{h}$ and $K_{X}$. Equation (6) may be used to eliminate $X_{S 1}$. The value of $f_{P}$ may be assumed (Table 1) and the value of $b_{H}$ can be evaluated independently, as described later. For SRT values in excess of 5 days, $S_{S}$ and $X_{S}$ will be negligibly small allowing $S_{S}, k_{h}$ and $K_{X}$ to be eliminated (Ekama et al., 1986). Thus, the value of $X_{n}$ is the only unknown. It can be evaluated by using a one dimensional search routine which chooses $X_{I 1}$ to minimize the error sum of squares when predicted sludge production rates are compared to measured rates as a function of SRT. This fitting acts to tune the model to the particular wastewater under study and compensates for any error made in the estimation of $Y_{H}$ and $b_{H}$. Once $X_{I 1}$ is known, $X_{S 1}$ can be calculated from equation (6). For variable strength influents it can generally be assumed that the various fractions stay in constant proportion to one another.

In most activated sludge modeling it is assumed that the concentration of biomass in the influent is negligible compared to the amount formed within the process. That approach is taken here, primarily because more research is needed regarding the impact of biomass in the influent. No procedure is recommended for measuring the influent concentrations. If there were a desire to include them in the model, appropriate microbiological methods would have to be employed.

Examination of Table 1 reveals that the model includes the soluble concentrations of oxygen, nitrate plus nitrite nitrogen, and alkalinity. The concentrations of all of these constituents in the feed may be measured by appropriate chemical tests.

Oxidizable nitrogen may be present in the feed in five forms: ammonia $\left(S_{\mathrm{NH} 1}\right)$; soluble, inert organic nitrogen $\left(S_{\mathrm{N} I 1}\right)$; particulate, inert organic nitrogen $\left(X_{\mathrm{N} I 1}\right)$; readily biodegradable organic nitrogen $\left(S_{\mathrm{N} D 1}\right)$; and slowly biodegradable organic nitrogen $\left(X_{\mathrm{N} D 1}\right)$. The concentration of ammonia in the feed may be determined by appropriate analysis of a filtered sample. The concentration of $S_{\mathrm{N} I}$ may be determined by performing Kjeldahl nitrogen tests on aliquots of the samples used to determine the soluble, inert COD. The Kjeldahl test may also be used to determine the total concentration of soluble organic nitrogen in the feed. Subtraction of $S_{\mathrm{N} n}$ from that value approximates $S_{\mathrm{N} D 1}$. If $S_{\mathrm{N} D 1}$ and $X_{\mathrm{N} D 1}$ are assumed to be proportioned in the same way as the readily biodegradable and slowly biodegradable COD in the feed, then $X_{\mathrm{N} D 1}$ may be determined once $S_{\mathrm{N} D 1}$ is known:

$$
\frac{S_{\mathrm{N} D 1}}{X_{\mathrm{N} D 1}+S_{\mathrm{N} D 1}}=\frac{S_{S 1}}{X_{S 1}+S_{S 1}}
$$

There is no need to determine $X_{\mathrm{N} l 1}$ since it does not appear in the model.

\section{Estimation of kinetic parameters}

The purpose of the half-saturation coefficients for oxygen $\left(K_{\mathrm{O}, H}\right.$ and $\left.K_{\mathrm{O}, A}\right)$ and for nitrate $\left(K_{\mathrm{NO}}\right)$ is to serve as switching functions. Consequently, the actual values used are not critical as long as they are of the appropriate order of magnitude and are small in comparison to operating conditions.

The most critical parameter for characterizing the growth of the autotrophic biomass if $\hat{\mu}_{A}$, the maximum specific growth rate. The recommended procedure for its determination is to measure $\hat{\mu}_{A}$ during a dynamic test on one of the completely mixed reactors, provided it is barely nitrifying and has a high dissolved oxygen concentration. The sludge wastage rate should be decreased to make the SRT greater than that required to achieve a high degree of nitrification and the concentration of nitrate nitrogen should be measured over time as it increases through growth of additional nitrifying bacteria. If the natural logarithm of the nitrate nitrogen concentration is plotted vs time, its slope will be $\hat{\mu}_{A}-1 / \theta_{X}-b_{A}^{\prime}$ where $\theta_{X}$ is the new SRT and $b_{A}^{\prime}$ is the traditional decay rate coefficient for the nitrifiers (Hall, 1974). Unlike the situation for heterotrophic cell mass, the traditional decay rate constant for autotrophic bacteria, $b_{A}^{\prime}$, is 
numerically equivalent to the specific decay rate coefficient in this model, $b_{A}$. Its value may be assumed (Table 2). Since $\theta_{X}$ is known, $\hat{\mu}_{A}$ may be calculated.

The half saturation coefficient for the nitrifying bacteria, $K_{\mathrm{NH}}$, can be determined by the infinite dilution procedure of Williamson and McCarty (1975) which provides information on the relationship between the specific nitrification rate and the pseudo-steady state ammonia concentration. That information can be analyzed to provide a value for $K_{\mathrm{NH}}$.

To determine the heterotrophic decay coefficient, $b_{H}$, sludge is removed from a completely mixed reactor and put into a batch reactor where the oxygen uptake rate can be measured many times over a period of several days (Ekama et al., 1986). The slope of a plot of the natural logarithm of the oxygen uptake rate vs time is the traditional heterotrophic decay coefficient, $b_{H}^{\prime}$. The model decay coefficient $b_{H}$ can be calculated with:

$$
b_{H}=\frac{b_{H}^{\prime}}{1-Y_{H}\left(1-f_{P}\right)} .
$$

The parameter $\eta_{g}$ is a correction factor which adjusts for either the change in $\hat{\mu}_{H}$ associated with anoxic conditions, or for the fact that only a portion of the biomass can denitrify (Batchelor, 1982); $\eta_{h}$ is a correction factor which adjusts for the observation that hydrolysis of slowly biodegradable organic matter occurs more slowly under anoxic conditions than under aerobic conditions. The tests to measure $\eta_{g}$ and $\eta_{h}$ are performed at the same time by evaluating oxygen and nitrate consumption rates in two batch reactors which are equivalent in every respect except for the terminal electron acceptor (oxygen in one and nitrate in the other). Immediately after bringing biomass into contact with wastewater in a batch reactor the activity in the reactor will be dominated by growth of the heterotrophs on the readily biodegradable substrate whereas later activity will be predominantly due to use of substrate arising from hydrolysis of the slowly biodegradable substrate (Ekama et al., 1986). If OUR $\mathrm{g}_{\mathrm{g}}$ represents the oxygen uptake rate during the first period in the aerobic reactor and $N_{U} R_{g}$ represents the nitrate utilization rate in the anoxic reactor, then,

$$
\eta_{g}=\frac{(2.86)\left(\mathrm{NUR}_{g}\right)}{\mathrm{OUR}_{g}}
$$

Likewise, if $\mathrm{OUR}_{h}$ represents the oxygen uptake during the second period and $\mathrm{NUR}_{h}$ the corresponding nitrate uptake rate, then

$$
\eta_{h}=\frac{(2.86)\left(\mathrm{NUR}_{h}\right)}{\mathrm{OUR}_{h}}
$$

The parameters describing biomass growth, $\hat{\mu}_{H}$ and $K_{S}$, are difficult to evaluate accurately, but that is not critical because the model is not very sensitive to their values. The main function of $\hat{\mu}_{H}$ is to allow the maximum oxygen uptake rate to be predicted. This suggests that measures of $\hat{\mu}_{H}$ should be based upon oxygen uptake measurements rather than cell growth or substrate removal. Cech et al. (1985) and Chudoba et al. (1985) have described a respirometric procedure for measuring both $\hat{\mu}_{H}$ and $K_{S}$.

An important factor which has only recently been recognized is that biomass grown in different reactor configurations exhibit different values of $\hat{\mu}_{H}$ and $K_{S}$ even though the reactors are operated at the same SRT, loading, etc. (Cech et al., 1985; Dold and Marais, 1986). This suggests that care must be used in the collection and interpretation of kinetic data. Preliminary evidence suggests that it would be acceptable to estimate $\hat{\mu}_{H}$ and $K_{S}$ using biomass from the completely mixed reactor receiving a daily cyclic square wave input of food that was used for determining the concentration of readily biodegradable substrate in the feed.

The final parameters to be evaluated are $k_{h}$, the maximum specific hydrolysis rate, and $K_{X}$, the halfsaturation coefficient for hydrolysis of slowly biodegradable organic matter. These, too, are most easily evaluated by operating a completely mixed activated sludge reactor at a short SRT with feed conforming to a daily cyclic square wave pattern (Ekama et al., 1986). The best way to estimate $k_{h}$ and $K_{X}$ is fitting the model response to the oxygen uptake pattern in Fig. 1 (Dold and Marais, 1986). Since all other parameters have been selected, the only unknowns for curve-fit are the two hydrolysis parameters, and the technique has been found to be quite sensitive to their values.

As seen in the preceding discussion, evaluation of the parameters and characterization of the wastewater must proceed in a particular order. Table 3 summarizes the sequence in which things must be done.

\section{TYPICAL PARAMETER RANGES}

Table 4 presents typical ranges for values of the stoichiometric and kinetic parameters at neutral $\mathrm{pH}$ and $20^{\circ} \mathrm{C}$ for domestic wastewater. While the model is relatively insensitive to some of these parameters (see Table 2) allowing assumed values to be used, it is quite sensitive to others. Furthermore, since some parameter values are strongly dependent on specific factors in the wastewater and on environmental conditions, the desirability of experimentally determining them cannot be overemphasized. Consequently, the values listed in Table 4 are presented simply to give the reader an appreciation for the range likely to be encountered. In reviewing them, it should be recognized that while some have been used in other models, thereby providing a reasonable body of knowledge from which to draw, others (e.g. $k_{h}, k_{a}$, $K_{X}, \eta_{g}, \eta_{h}$ ) are relatively new so that the ranges given are tentative at best. As the model is used and more 
Table 3. Parameters and characteristics which must be evaluated and information needed

\begin{tabular}{|c|c|c|}
\hline Symbol & Name & $\begin{array}{l}\text { Prior information } \\
\text { needed }\end{array}$ \\
\hline$S_{\mathrm{NO} 1}$ & $\begin{array}{l}\text { Soluble nitrate nitrogen concentration } \\
\text { in wastewater }\end{array}$ & \\
\hline$S_{\mathrm{NH} 1}$ & $\begin{array}{l}\text { Soluble ammonia nitrogen concentration } \\
\text { in wastewater }\end{array}$ & \\
\hline$S_{11}$ & $\begin{array}{l}\text { Soluble inert } \mathrm{COD} \text { concentration in } \\
\text { wastewater }\end{array}$ & \\
\hline$S_{\mathrm{N} / 1}$ & $\begin{array}{l}\text { Soluble inert organic nitrogen } \\
\text { concentration in wastewater }\end{array}$ & \\
\hline$S_{\mathrm{N} D \mathrm{I}}$ & $\begin{array}{l}\text { Soluble biodegradable organic } \\
\text { nitrogen concentration in wastewater }\end{array}$ & $S_{\mathrm{N} / 1}$ \\
\hline$Y_{H}$ & Yield for heterotrophic biomass & \\
\hline$S_{S 1}$ & $\begin{array}{l}\text { Concentration of readily biodegradable } \\
\text { COD in wastewater }\end{array}$ & $Y_{H}$ \\
\hline$\hat{\mu}_{A}$ & $\begin{array}{l}\text { Maximum specific growth rate for } \\
\text { autotrophic biomass }\end{array}$ & $b_{A}$ \\
\hline$K_{\mathrm{NH}}$ & $\begin{array}{l}\text { Ammonia half-saturation coefficient } \\
\text { for autotrophic biomass }\end{array}$ & \\
\hline$b_{H}$ & $\begin{array}{l}\text { Decay coefficient for heterotrophic } \\
\text { biomass }\end{array}$ & $Y_{H}, f_{P}$ \\
\hline$X_{I 1}$ & $\begin{array}{l}\text { Inert suspended organic matter } \\
\text { concentration in wastewater }\end{array}$ & $f_{P}, b_{H}, S_{S 1}, S_{I 1}$ \\
\hline$X_{S 1}$ & $\begin{array}{l}\text { Slowly biodegradable organic matter } \\
\text { concentration in wastewater }\end{array}$ & $X_{n 1}, S_{S 1}, S_{n}$ \\
\hline$X_{\mathrm{N} D 1}$ & $\begin{array}{l}\text { Slowly biodegradable organic nitrogen } \\
\text { concentration in wastewater }\end{array}$ & $S_{S 1}, X_{S 1}, S_{\mathrm{N} D 1}$ \\
\hline$\eta_{g}$ & $\begin{array}{l}\text { Correction factor for } \hat{\mu}_{H} \text { under anoxic } \\
\text { conditions }\end{array}$ & \\
\hline$\eta_{h}$ & $\begin{array}{l}\text { Correction factor for hydrolysis under } \\
\text { anoxic conditions }\end{array}$ & \\
\hline$\hat{\mu}_{H}$ & $\begin{array}{l}\text { Maximum specific growth rate } \\
\text { for heterotrophic biomass }\end{array}$ & $Y_{H}, X_{S 1}, X_{I !}, S_{S 1}, f_{P}$ \\
\hline$K_{S}$ & $\begin{array}{l}\text { Half-saturation coefficient for } \\
\text { heterotrophic biomass }\end{array}$ & $Y_{H}, X_{S 1}, X_{I 1}, S_{S 1}, f_{P}$ \\
\hline$k_{h}$ & Maximum specific hydrolysis rate & \\
\hline$K_{X}$ & $\begin{array}{l}\text { Half-saturation coefficient for hydrolysis } \\
\text { of slowly biodegradable substrate }\end{array}$ & \\
\hline
\end{tabular}

studies are performed, our knowledge of expected parameter values will expand.

Among environmental conditions, $\mathrm{pH}$ and temperature are of primary importance. The effects of $\mathrm{pH}$ on nitrification have been studied extensively and quantitative relationships have been proposed in the literature. Heterotrophic activity is also influenced by
$\mathrm{pH}$, but to a lesser extent so that few relationships are available. Nevertheless, the importance of $\mathrm{pH}$ should be recognized. Both nitrification and denitrification involve changes which can alter the $\mathrm{pH}$ if the alkalinity of the wastewater is not adequate. Consequently, the model was structured in a way which allows alkalinity changes to be calculated, thereby

Table 4. Typical parameter values at neutral $\mathrm{pH}$ and $20^{\circ} \mathrm{C}$ for domestic wastewater

\begin{tabular}{|c|c|c|}
\hline \multirow[b]{2}{*}{ Symbol } & Units & \multirow[b]{2}{*}{ Value } \\
\hline & Stoichiometric parameters & \\
\hline$Y_{A}$ & $\mathrm{~g}$ cell $\mathrm{COD}$ formed $(\mathrm{g} \mathrm{N} \text { oxidized })^{-1}$ & $0.07-0.28$ \\
\hline$Y_{H}^{A}$ & $\mathrm{~g}$ cell COD formed (g COD oxidized $)^{-1}$ & $0.46-0.69$ \\
\hline$f_{P}^{n}$ & dimensionless & 0.08 \\
\hline$i_{X B}$ & $\mathrm{gN}(\mathrm{g} \mathrm{COD})^{-1}$ in biomas & 0.086 \\
\hline \multirow[t]{2}{*}{$i_{X P}$} & $\mathrm{~g} \mathrm{~N}(\mathrm{~g} \mathrm{COD})^{-1}$ in products from biomass & 0.06 \\
\hline & Kinetic parameters & \\
\hline$\hat{\mu}_{H}$ & $\mathrm{day}^{-1}$ & $3-13.2$ \\
\hline$K_{S}$ & $\mathrm{~g} \mathrm{COD} \mathrm{m}^{-3}$ & $10-180$ \\
\hline$K_{\mathrm{O}, H}$ & $\mathrm{gO}_{2} \mathrm{~m}^{-3}$ & $0.01-0.15$ \\
\hline$K_{\mathrm{NO}}$ & $\mathrm{g} \mathrm{NO}_{3}-\mathrm{N} \mathrm{m}^{-3}$ & $0.1-0.2$ \\
\hline$b_{H}$ & day $^{-1}$ & $0.09-4.38$ \\
\hline$\eta_{g}$ & dimensionless & $0.6-1.0$ \\
\hline $\begin{array}{ll}\lg \\
\eta_{h}\end{array}$ & dimensionless & 0.4 \\
\hline$k_{a}^{n}$ & $\mathrm{~m}^{3}(\mathrm{~g} \text { cell COD } \cdot \text { day })^{-1}$ & 0.016 \\
\hline$k_{h}$ & g slowly biodegradable COD $(\mathrm{g} \text { cell } \mathrm{COD} \cdot \text { day })^{-1}$ & 2.2 \\
\hline$K_{X}^{n}$ & g slowly biodegradable COD $(\mathrm{g} \text { cell COD })^{-1}$ & 0.15 \\
\hline$\hat{\mu}_{A}$ & day $^{-1}$ & $0.34-0.65$ \\
\hline$K_{\mathrm{NH}}$ & $\mathrm{g} \mathrm{NH}_{3}-\mathrm{N} \mathrm{m}^{-3}$ & $0.6-3.6$ \\
\hline$K_{\mathrm{O}, A}$ & $\mathrm{~g} \mathrm{O}_{2} \mathrm{~m}^{-3}$ & $0.5-2.0$ \\
\hline$b_{A}, A$ & $\mathrm{day}^{-1}$ & $0.05-0.15$ \\
\hline$k_{A}$ & $\mathrm{~m}^{3} \mathrm{COD}(\mathrm{g} \cdot \mathrm{day})^{-1}$ & 0.08 \\
\hline
\end{tabular}


permitting the user to check to be sure that the assumption of nearly constant $\mathrm{pH}$ is not violated.

Within a narrow temperature range, an increase in temperature generally results in an increase in the value of a rate coefficient like $\hat{\mu}, b$, or $k_{h}$ in a manner that can be described by a modified Arrhenius equation. Because half-saturation coefficients are not rate coefficients it is more difficult to generalize about the effects of temperature upon them. The important point to recognize, however, is that all kinetic parameters are influenced by temperature. This suggests that their values should be determined at the temperature which will impose the most critical condition on the facility.

\section{ASSUMPTIONS, RESTRICTIONS AND CONSTRAINTS}

Modeling of a system as complex as a single-sludge wastewater treatment system requires that certain simplifications and assumptions be made to make the model tractable. To prevent their violation it is important that they be stated explicitly.

Assumptions and restrictions associated with the model

(1) The system operates at constant temperature and the parameter values are appropriate for the particular temperature assumed.

(2) The $\mathrm{pH}$ is constant and near neutrality.

(3) The nature of the organic matter is constant although its concentration may vary.

(4) Sufficient nutrients are present to allow balanced growth of the biomass.

(5) The correction factors for denitrification, $\eta_{g}$ and $\eta_{h}$, are fixed and constant for à given wastewater. It is possible that their values are influenced by system configuration but this is not considered.

(6) The coefficients for nitrification do not change as other waste constitutents are removed.

(7) The heterotrophic biomass is homogeneous and does not undergo changes in species diversity with time.

(8) The entrapment of particulate organic matter in the biomass is instantaneous.

(9) Hydrolysis of organic matter and organic nitrogen are coupled and occur simultaneously with equal rates.

(10) The type of electron acceptor present does not affect the loss of active biomass by decay.

\section{Constraints on application of the model}

Constraints are necessary to ensure that the simulation results have practical utility.

(1) The net growth rate or SRT of the biomass must be within the range that allows a sludge with good settling characteristics to develop. Typically, the SRT should lie between 3 and 30 days.

(2) The reactor configuration should be such that the activated sludge concentration entering the settler is between 750 and $7500 \mathrm{~g} \mathrm{~m}^{-3}$ in order to achieve proper sludge settling.

(3) The unaerated fraction of the reactor volume should not exceed $50 \%$ because larger fractions may cause deterioration of sludge settling characteristics.

(4) The mixing intensity associated with oxygen transfer should not exceed $240 \mathrm{~s}^{-1}$ to prevent excessive floc shear. This must be considered during selection of the reactor sizes.

\section{IMPLEMENTATION OF THE ACTIVATED SLUDGE MODEL}

The full potential of the model presented herein will only be realized if it is implemented in computer codes which are simple to use and available to design engineers in offices of all sizes. Heretofore, simulation of complex activated sludge systems was limited to researchers with access to large computers. Recent advances in the development of rapid and powerful microcomputers, however, now make it possible for even the smallest engineering office to have substantial computing power. The computer power resident in an IBM-PC/XT or equivalent machine equipped with an 8087 math coprocessor is adequate to handle a model of the type presented here, even for simulation of the time-dependent response of a system to typical diurnal patterns in flow and concentration. Although considerable space in the task group report was devoted to strategies for developing computer codes, it is impossible to present all of that information here. However, it is important that several points be made.

First, compiled languages such as BASIC and Pascal are sufficient to implement a powerful code. Second, even complex flow schemes can be modeled as simple tanks-in-series systems, thereby simplifying the computer code and its use. For example, Fig. 2 illustrates several common processes and their model analogs. By careful consideration of the important system characteristics the number of systems which could be simulated is almost limitless. Third, considerable computation time can be saved by proper consideration of the step sizes used during numerical integration. For example, changes in DO concentrations occur with time constants on the order of seconds whereas the time constants associated with other soluble constituents are in the order of minutes and those associated with particulate constituents are in the order of hours. This means that numerical integrations can be nested by using different step sizes for different constituents. Fourth, the final settler can be considered to be a separation point. While this means that the model will not give a true dynamic simulation of an activated sludge system in which large transfers of solids occur between the aeration basins and the settler, it will still give reasonable time-dependent responses of systems which are operated with underloaded clarifiers. Finally, by simplifying the process rate expressions to appropriate 


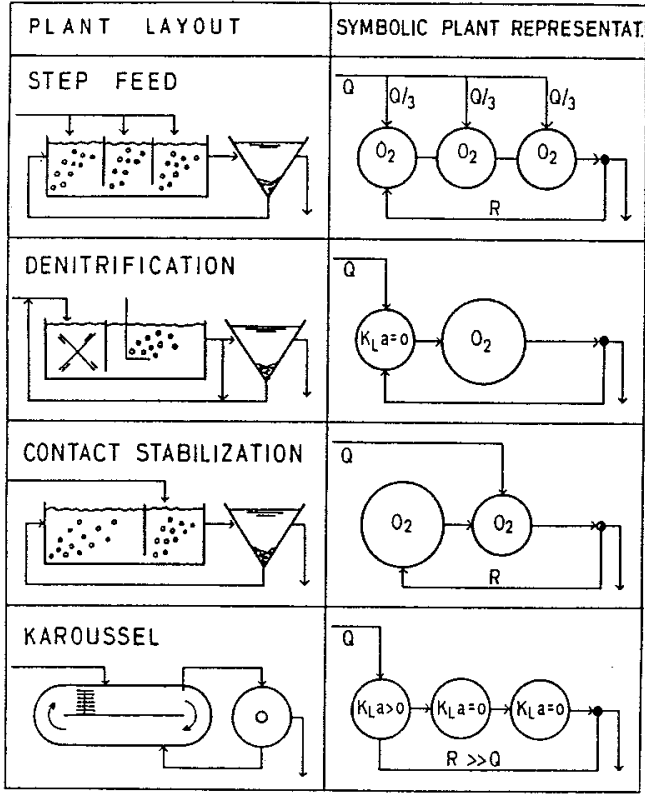

Fig. 2. Examples of systems which may be used to represent complex activated sludge flow schemes.

first order kinetics, matrix inversion and solution can be used to obtain initial estimates of reactor constituents for use in initializing the numerical integration routines, thereby saving computer time.

All of the task group members either have developed or have access to microcomputer codes for implementing the model. While they vary in their sophistication and speed, all are easy to use and are representative of what can be accomplished with the model.

\section{CONCLUSION}

A model, such as the one presented here, can have several beneficial effects upon the practice of environmental engineering. By allowing exploration through simulation of a broad range of system configurations, inputs, and operational strategies, it greatly expands an engineers experience base and increases his intuitive decision-making ability. Once calibrated to a particular wastewater, a model allows the engineer to screen a large number of potential designs and eliminate those which are inefficient from either a process or an economic perspective. Furthermore, once a design has been selected a model allows the units within the system to be sized so as to minimize system cost. Finally, after a plant has been constructed, a model can be used to investigate alternative operational strategies to minimize the impact of new waste loads.

It is the hope of the task group that the model presented herein will be used by practicing environmental engineers, thereby bringing them the benefits listed above. Furthermore, it is hoped that this model will cause both practitioners and researchers to ask critical questions about the events occurring in singlesludge systems, thereby stimulating additional research which will lead to a better understanding of them.

\section{REFERENCES}

Batchelor B. (1982) Kinetic analysis of alternative configurations for single-sludge nitrification/denitrification. J. Wat. Pollut. Control Fed. 54, 1493-1504.

Cech J. S., Chudoba J. and Grau P. (1985) Determination of kinetic constants of activated sludge microorganisms. Wat Sci. Technol. 17, $259-272$.

Chudoba J., Cech J. S., Farkac J. and Grau P. (1985) Control of activated sludge filamentous bulking: experimental verification of a kinetic selection theory. Wat. Res. 19, 191-196.

Dold P. L. and Marais G. v. R. (1986) Evaluation of the general activated sludge model proposed by the IAWPRC task group. Water Sci. Technol. 18, 63-89.

Dold P. L., Ekama G. A. and Marais G. v. R. (1980) A general model for the activated sludge process. Prog. Wat. Technol. 12, 47-77.

Downing A. L., Painter H. A. and Knowles G. (1964) Nitrification in the activated sludge process. J. Proc. Inst. Sewage Purif. 64, 130-158.

Ekama G. A., Dold P. L. and Marais G. v. R. (1986) Procedures for determining influent COD fractions and the maximum specific growth rate of heterotrophs in activated sludge systems. Water Sci. Technol. 18, 91-114.

Gaudy A. F. Jr and Gaudy E. T. (1971) Biological Concepts for Design and Operation of the Activated Sludge Process. U.S. Environmental Protection Agency Water Pollution Research Series, Report No. 17090, FQJ, 09/71.

Grady C. P. L. Jr and Lim H. C. (1980) Biological Wastewater Treatment, Theory and Applications. Marcel Dekker, New York.

Grady C. P. L. Jr, Gujer W., Henze M., Marais G. v. R. and Matsuo T. (1986) A model for single-sludge wastewater treatment systems. Wat Sci. Technol 18, 47-61.

Grau P., Sutton P. M., Henze M., Elmaleh S., Grady C. P. L. Jr, Gujer W. and Koller J. (1982) Recommended notation for use in the description of biological wastewater treatment processes. Wat. Res. 16, 1501-1505.

Hall I. R. (1974) Some studies on nitrification in the activated sludge process. Wat. Pollut. Control 73, 538-547.

McKinney R. E. and Ooten R. J. (1969) Concepts of complete mixing activated sludge. Trans. 19th Sanit. Engng Conf. Univ. Kansas, pp. 32-59.

Petersen E. E. (1965) Chemical Reaction Analysis. Prentice-Hall, Englewood Cliffs, N.J.

Scearce S. N., Benninger R. W., Weber A. S. and Sherrard J. H. (1980) Predictions of alkalinity changes in the activated sludge process. J. Wat. Pollut. Control Fed. 52, 399-405.

Van Haandel A. C., Ekama G. A. and Marais G. v. R. (1981) The activated sludge process-III. Single sludge denitrification. Wat. Res. 15, 1135-1152.

Water Research Commission (1984) Theory, Design and Operation of Nutrient Removal Activated Sludge Processes. Water Research Commission, P.O. Box 824, Pretoria 0001 , South Africa.

Weddle C. L. and Jenkins D. (1971) The viability and activity of activated sludge. Wat. Res. 5, 621-640.

Williamson K. J. and McCarty P. L. (1975) Rapid measurement of Monod half-velocity coefficients for bacterial kinetics. Biotechnol. Bioengng 17, 915-924. 